\title{
O DESENVOLVIMENTO MEANDROSO DA EDUCAÇÃO BRASILEIRA ENTRE O ESTADO E O MERCADO
}

\author{
Luiz AnTônio CunHA*
}

MEANDRO: s.m. 1 - Sinuosidade, rodeio, volteio de curso de água, de caminho etc. 2. Fig - Emaranhamento, complicação, dificuldade; 3 - Fig. Enredo, intriga, confusão.

(Novo Aurélio - O Dicionário da Língua Portuguesa)

\begin{abstract}
RESUMO: O artigo questiona a imagem da privatização da educação brasileira como um processo generalizado e contínuo. Defende que a privatização consiste num processo cheio de meandros, que não comporta resposta simples, porque as forças que a determinam ora incentivam o crescimento do setor público, ora do setor privado, ora de ambos. Como sustentação da argumentação, é examinada a legislação federal relativa aos incentivos às instituiçóes privadas nas últimas quatro décadas, assim como as estatísticas de alunos dos três níveis de ensino. $\mathrm{O}$ autor chama a atenção para o fato de que o aumento do número de alunos do ensino médio público gera uma nova qualidade, que exige um novo currículo. $\mathrm{O}$ artigo conclui que o caráter meandroso dessas fronteiras expressa, de um lado, uma crise de hegemonia no que concerne à natureza do Estado republicano e, de outro, o travamento de uma qualidade de que a educação brasileira carece, qual seja, a da clareza na distinção entre o público e o privado, em sua dimensão institucional e curricular.
\end{abstract}

Palavras-chave: Educação brasileira. Privatização. Políticas públicas.

Doutor em Educação e professor titular da Faculdade de Educação da Universidade Federal do Rio de Janeiro (UFRJ). Homepage: www.luizantonio.cunha.nom.br 


\title{
The MEANDERING DEVELOPMENT OF Brazilian EDUCATION BETWEEN STATE AND MARKET
}

\begin{abstract}
The present study seeks to question the image of the privatization of Brazilian education, which is presented as a generalized and ongoing process. It argues that this privatization process is full of meanders and does not accept simple answers because it is established by forces that sometimes stimulate the growth of the public sector, sometimes that of the private sector and sometime that of both. To support this argument, it explores both the federal legislation on incentives to private institutions passed these last four decades and the statistics on students in the three levels of education. The author highlights the fact that the increase in the number of secondary public school students generates a new quality that demands a new curriculum. The paper concludes that the meandering character of such frontiers demonstrates, on the one hand, a crisis of hegemony with regard to the nature of the republican State and, on the other, the hampering of a type of quality that is missing in Brazilian education: a clear distinction between the public and private spheres in its institutional and curricular dimensions.
\end{abstract}

Key words: Brazilian education. Privatization. Public policies.

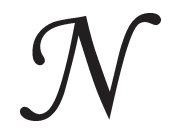

este texto, questiono a imagem do desenvolvimento da educação brasileira como um processo generalizado e contínuo de privatização. No meu entender, a privatização é um processo cheio de meandros, que não comporta resposta simples. Isso porque a segmentação dos sistemas educacionais não obedece a um trajeto retilíneo, sendo determinada por forças que ora incentivam o crescimento do setor público, ora do setor privado, ora de ambos. Esta é a conclusão a que cheguei, e que antecipo ao leitor.

As forças em conflito, que determinam a segmentação dos sistemas educacionais, são o Estado e o Mercado, aqui definidos como categorias empíricas. ${ }^{1}$ Compreendem o Estado o Ministério da Educação, o Conselho Nacional (ou Federal) de Educação, o Conselho Nacional dos Secretários Estaduais de Educação e a União Nacional dos Dirigentes Municipais de Educação, assim como as instituições públicas de ensino. Compreendem o Mercado as instituições privadas de ensino e suas entidades representativas, como a Associação Brasileira de Entidades Mantenedoras, a Associação Nacional das Universidades 
Particulares, a Associação de Educação Católica do Brasil, o Conselho Geral das Instituições Metodistas de Ensino, a Associação Nacional de Faculdades e Institutos Superiores, entre outras.

No cruzamento do Estado com o Mercado encontram-se as entidades corporativas, como os conselhos federais e regionais de diversas profissões, inclusive a Ordem dos Advogados do Brasil (OAB), que atuam como órgãos para-estatais de regulação. Instituídas por lei do Congresso, algumas delas são ouvidas na criação de cursos superiores, como os de Direito, Medicina, Odontologia e Engenharia. Assim, as entidades corporativas exercem papel importante e direto na regulação do fluxo de profissionais nas respectivas profissões. A OAB, caso extremo, realiza exame para credenciar os formados nos cursos de Direito a exercerem a profissão de advogado. Outras entidades, como o Conselho Federal de Engenharia, Arquitetura e Agronomia e o Conselho Federal de Medicina, delimitam as fronteiras entre as atividades profissionais que os concluintes de cursos técnicos de nível médio podem exercer, resguardando atribuiçóes e oportunidades aos diplomados por cursos superiores. Os sindicatos, tanto os de empregadores quanto os de empregados (professores e funcionários), também estão no cruzamento do Estado com o Mercado. Do Estado eles têm a cobertura legal da unicidade por categoria e a garantia de financiamento pelo imposto pago por todos os associados. Do Mercado eles têm o objeto concreto e unificador de sua atuação, como o valor dos salários e as condições de emprego e trabalho. Embora sejam órgãos do Estado, os conselhos de educação (federal/nacional, estaduais e municipais) podem estar mais ou menos penetrados pelo Mercado, conforme as circunstâncias políticas.

\section{Subsídios indiscriminados}

O regime militar (1964/1985) favoreceu enormemente a iniciativa privada no campo educacional. Não porque as Forças Armadas fossem espontaneamente privatistas, mas, sim, porque os agentes e colaboradores do golpe de Estado de 1964 fizeram parte ou tinham afinidades político-ideológicas com os grupos que defenderam o Projeto de Lei de Diretrizes e Bases da Educação Nacional (LDB), de orientação privatista, que deu origem à Lei n. 4.024, de dezembro de 1961. A estruturação dos sistemas de ensino previstos pela primeira 
LDB favoreceu os interesses privados, por atribuir aos conselhos de educação (o federal e os estaduais) importantes competências antes concentradas nos detentores dos cargos executivos. Os membros desses conselhos, nomeados livremente pelo Presidente da República e pelos governadores dos estados, recaíram em pessoas escolhidas mediante pressão e articulação privadas. Complementarmente, esses conselheiros ficaram expostos a pressōes e atrativos de diversas espécies. Além disso, divididos os centros de tomada de decisão, tornou-se mais difícil a resistência às pressões e aos atrativos das instituições privadas de ensino.

Contraditoriamente, desde os anos do "milagre econômico", a ampliação das camadas médias propiciou uma clientela ávida de escola privada, não só como símbolo de status prestigioso, mas, também, como alternativa para o ensino público que se deteriorava a cada ano, justamente por força das políticas elaboradas e implementadas pelos empresários do ensino e seus prepostos, que ocupavam os postos diretivos dos sistemas de educação, nos níveis federal, estadual e municipal.

Vários têm sido os mecanismos pelos quais os empresários do ensino conseguiram o apoio governamental para seus empreendimentos: imunidade fiscal, garantia de pagamento das mensalidades pelos alunos, mediante bolsas de estudo distribuídas pelo poder público, e até mesmo a inibição de iniciativas governamentais de criação e/ou ampliação de escolas, para disporem de uma espécie de reserva de mercado. Mais do que isso, as instituições educacionais receberam incentivos fiscais para financiar diretamente seus empreendimentos.

Não bastassem os recursos transferidos às escolas privadas, sob a forma de bolsas de estudos para os alunos, a acumulação de capital no campo educacional foi fortemente favorecida pela reforma tributária do primeiro governo militar.

A Constituição de 1946 trazia um dispositivo que assegurava a isenção tributária para as instituiçõoes de educação, vedando à União, aos estados e aos municípios o lançamento de impostos sobre seus bens e serviços, desde que suas rendas fossem integralmente aplicadas no país e para os fins educacionais. Na reforma constitucional de 1965, os privilégios fiscais dessas instituições foram ampliados, estendendo-se a isenção de impostos para suas rendas. A Constituição de 1967 e a Emenda de 1969 mantiveram esse dispositivo. Assim, as escolas privadas passaram a gozar de uma verdadeira imunidade fiscal, o que ampliou suas possibilidades de acumulação de capital. 
Em complementação à isenção tributária, o governo federal estendeu seu apoio mediante a criação de um mecanismo de aporte de recursos financeiros aos estabelecimentos privados. Neste sentido, o Decreto n. 72.485/73, que estabeleceu "normas para a concessão de amparo técnico e financeiro às entidades particulares de ensino", recomendou aos governos estaduais que evitassem a criação de estabelecimentos públicos de ensino onde as escolas privadas fossem consideradas suficientes para absorver a demanda efetiva ou capazes de expandir a oferta para atender à demanda contida. Os conselhos estaduais de educação receberam a incumbência de baixar normas complementares, o que facilitou sobremaneira o atendimento dos interesses dos empresários do ensino, que tinham representação majoritária nesses órgãos colegiados.

\section{Inflexão na transição}

A transição para a democracia levou a uma inflexão na política de subsídios indiscriminados às instituições privadas de ensino.

Como mostrei no livro Educação, Estado e democracia no Brasil, publicado ao início da década de 1990, esse processo ocorreu, no Brasil, da periferia para o centro e do nível municipal do Estado ao nível federal, passando pelo estadual. Sem absolutizar esse sentido, mostrei que, no campo educacional, foi no plano municipal onde, primeiramente, foram elaboradas e implementadas políticas que tinham demandas populares como referência imediata. Contudo, foi com as eleições diretas para governadores, em 1982, que a transição para a democracia teve um impulso decisivo.

Com efeito, a eleição de Tancredo Neves (MG), Leonel Brizola (RJ) e Franco Montoro (sP), candidatos de oposição aos governos militares, para dirigirem os estados mais importantes do país, em termos econômicos e políticos, abriu caminho para um novo protagonismo das secretarias de educação, como ficou patente com Darcy Ribeiro, no Rio de Janeiro, e com a dupla Otávio Elísio Alves de Brito e Neidson Rodrigues, em Minas Gerais. Para eles, ao invés de transferirem recursos para as instituições privadas, os governos estaduais deveriam atuar diretamente, mediante suas próprias redes escolares. Mesmo que os resultados obtidos não fossem exatamente os almejados, nesses estados, como em outros, as demandas populares foram sendo cada vez mais respondidas, adequadamente ou não, mas sempre de modo direto pelas 
redes escolares públicas. Por exemplo, em Minas Gerais, a supressão do privilégio que a legislação concedia ao sindicato das escolas particulares em aprovar ou não a instalação de novas escolas públicas e até mesmo a extensão de sua atividade teve, como compensação, um lote generoso de bolsas de estudo nas escolas privadas, ao velho estilo; no Rio de Janeiro, apesar de toda a concentração de recursos na construção de prédios para a instalação de escolas do primeiro segmento do ensino de $1^{\circ}$ grau, em tempo integral, foi no ensino de $2^{\circ}$ grau oferecido pela rede estadual que as matrículas realmente cresceram.

Impulsionada, então, pelos governos estaduais do período 1983/ 87, a legislação federal foi induzida a mudar seu rumo, o que se acelerou pela eleição do primeiro Presidente da República civil, em 1985, depois de duas décadas de governos militares, e a convocação da Assembléia Nacional Constituinte. O ponto mais importante foi, sem dúvida, a proibição de as empresas transferirem para escolas privadas os recursos (no todo ou em parte) devidos ao salário-educação. Vale à pena fazer uma pequena digressão sobre esse ponto.

A Constituição de 1946 criou um tributo para as empresas, denominado salário-educação, o qual só foi regulamentado em 1964. As empresas ficaram sujeitas a uma contribuição, calculada à base de 1,4\% (2,5\% depois da Lei n. 5.692/71) do valor da folha de pagamento, para financiar o ensino primário (depois $1^{\circ}$ grau) dos trabalhadores $\mathrm{e}$ seus filhos. Ao invés de recolherem a contribuição, as empresas poderiam optar por manter escola própria ou transferir os recursos devidos a instituiçôes educacionais privadas, a título de bolsas de estudo para alunos "da comunidade", não necessariamente de seus empregados ou seus filhos. Depois de décadas de abusos, o Decreto n. 91.796/85 garantiu a manutenção dos alunos que, na época, freqüentavam escola privada com recursos diretamente transferidos pelas empresas, mas vedou que novos alunos fossem atendidos por essa via. A partir daí, os recursos devidos pelas empresas deveriam ser recolhidos ao Fundo $\mathrm{Na}$ cional de Desenvolvimento da Educação, que os repassaria aos governos estaduais, conforme os critérios estabelecidos em lei. Não vedava, porém, a concessão de bolsas de estudo às escolas privadas pelos governos estaduais.

Promulgada a Constituição, em 1996, o Presidente Fernando Henrique Cardoso e seu ministro da Educação, Paulo Renato Souza, 
desfecharam iniciativas de mudança legislativa em vários domínios, desde o ensino profissional até o ensino superior. No que concerne ao financiamento do ensino fundamental, a Emenda Constitucional n. 14/ 96 criou o Fundo de Manutenção e Desenvolvimento do Ensino Fundamental e Valorização do Magistério (FUNDEF). Este Fundo contábil promoveu nova forma de realocaçáo de recursos entre as redes estadual e municipais, em cada unidade da Federação, reservando para o ensino público, nesse nível, pelo menos $60 \%$ dos $25 \%$ garantidos pela Constituição para aplicação mínima na educação.

A legislação do salário-educação só foi mudada, significativamente, no governo Lula, quando a Lei n. 10.832/2003 determinou que os recursos advindos da quota estadual e municipal seriam divididos proporcionalmente ao número de alunos das respectivas redes escolares, no ensino fundamental, em cada unidade da Federação. Ou seja, utilizava-se o mesmo critério do FUNDEF. ${ }^{2}$ Com isso, dois terços dos recursos do salário-educação (quota estadual e municipal) passaram a ser destinados, exclusivamente, para o ensino público fundamental, ficando em aberto o destino da quota federal, no que diz respeito aos setores público e privado.

\section{Subsídios discriminados}

Diminuído, então, o aporte de recursos públicos para o ensino fundamental privado, a busca da acumulação de capital deslocou-se ainda mais fortemente para o nível superior, que já mostrava crescente rentabilidade desde a segunda metade da década de 1960 . Com efeito, o lento crescimento da oferta de educação pública em nível superior levou a demanda para o setor privado. $\mathrm{O}$ ensino médio, sem mecanismos próprios de financiamento, permaneceu como variável dependente da pressão dos concluintes do ensino fundamental.

É fato conhecido a situação de ginásios privados que passaram a abrigar faculdades no período da noite, em todo o país. A expansão das faculdades levou à abertura de outras e mais outras, dando origem a federaçôes, posteriormente alçadas ao nível de universidades, que, além do status prestigioso, tinham a vantagem de poder abrir cursos e ampliar o número de vagas, sem prévia autorização do poder público. Vale dizer, maior poder de adequação às forças do Mercado. Essa 
expansão foi acompanhada pela construção de grandes prédios, propiciada pelas isenções fiscais, pelos empréstimos a juros negativos, quando não a fundo perdido.

Na segunda metade da década de 1990, já no governo FHC, a promulgação da LDB trouxe novos elementos ao processo meandroso aqui descrito. Ela reconheceu, pela primeira vez na legislação brasileira, a possibilidade de lucro para as instituiçóes privadas de ensino: as particulares, no sentido estrito, definidas, implicitamente, por oposição às instituições privadas sem fins lucrativos (comunitárias, confessionais e filantrópicas).

Começou aí, no meu entender, uma tentativa de substituir o capitalismo patrimonial, vigente desde a formação do Estado nacional, pelo capitalismo concorrencial, no qual o investimento deixaria de usufruir de condições tão acintosamente privilegiadas, quando comparadas às de qualquer outro setor econômico. Dito de outro modo, não haveria por que uma instituição lucrativa estar isenta dos tributos que incidem sobre todas as outras. A finalidade educacional não seria justificativa aceitável pelo Mercado para diferenciá-la das produtoras de outras mercadorias. Ou seja: a concepção mercantil da educação implicaria a supressão de privilégios para os investimentos na sua produção e comercialização.

O corolário desse dispositivo da LDB foi a Medida Provisória n. 1.477-35, de 15 de abril de 1997 . Reeditando as normas contenedoras dos aumentos abusivos de mensalidades escolares dos estabelecimentos privados de ensino, em todos os níveis, ela inseriu matéria mais ampla, estabelecendo critérios para distinguir as entidades privadas com e sem finalidades lucrativas no ensino superior.

Ela determinou, ainda, que as entidades mantenedoras que assumissem sua finalidade não lucrativa deveriam reorganizar-se, de modo a atenderem aos seguintes requisitos: contar com um conselho fiscal, dotado de representação acadêmica; publicar anualmente seu balanço, certificado por auditores independentes; submeter-se a auditoria pelo poder público, a qualquer tempo; comprovar a aplicação dos seus excedentes financeiros para os fins da instituição mantida; comprovar a não-remuneração ou concessão de vantagens ou benefícios, por qualquer forma ou título, a seus instituidores, dirigentes, sócios, conselheiros ou equivalentes; comprovar a destinação de seu patrimônio a outra 
instituição congênere ou ao poder público, no caso de encerramento de suas atividades; e, finalmente, comprovar a destinação de pelo menos dois terços de sua receita operacional à remuneração do corpo docente e técnico-administrativo. No mesmo dia em que foi baixada a medida provisória, o Decreto n. 2.207/97 regulamentou o Sistema Federal de Ensino e especificou os procedimentos que as entidades mantenedoras deveriam adotar para explicitarem sua finalidade - lucrativa ou não.

As entidades mantenedoras com finalidades lucrativas receberam um prazo curto para alterarem sua natureza jurídica, após o que deveriam submeter os novos estatutos ao Ministério da Educação, para serem recredenciadas. Elas teriam de se submeter à legislação que rege as sociedades mercantis, especialmente no que concerne aos encargos fiscais, parafiscais e trabalhistas. Em conseqüência, deixaria de existir a imunidade fiscal para essas entidades. A partir de então, elas ficariam sujeitas ao pagamento de impostos sobre o patrimônio, a renda e os serviços prestados.

A medida provisória e o decreto foram prontamente repudiados pelos dirigentes das instituições privadas de ensino. Eles rejeitaram o que consideraram uma interferência indevida do governo na iniciativa privada, fora do âmbito do ensino propriamente dito, por pretender regular o funcionamento das entidades mantenedoras. Não bastasse isso, recusaram, também, a prática do recredenciamento, em especial o estabelecimento de etapas intermediárias e requisitos adicionais para que as universidades atingissem os patamares relativos ao corpo docente previstos pela LDB-96.

A ofensiva das Instituições de Ensino Superior (IES) privadas obteve resultado, ao menos parcial. O Decreto n. 2.306/97, baixado quatro meses após a medida provisória em questão, fez recuar a posição do Ministério da Educação em vários pontos. Para as entidades sem fins lucrativos, ele suprimiu a exigência de representação acadêmica no conselho fiscal de cada entidade mantenedora; permitiu que, ao invés dos balanços, fossem publicados apenas demonstrativos do movimento financeiro; a parcela da receita (apenas das mensalidades escolares) destinada ao pagamento de professores e funcionários caiu para $60 \%$, incluindo-se, nesse cômputo, os descontos, as bolsas de estudo concedidas e os encargos e benefícios sociais dos hospitais de ensino. 
As entidades com fins lucrativos livraram-se do prazo para alteração de seus estatutos, mas foi mantida a exigência de se submeterem à auditoria pelo poder público, devendo, ainda, publicarem anualmente demonstraçóes financeiras certificadas por auditores independentes.

Todavia, os efeitos fiscais dessas normas, mesmo atenuadas pelo Decreto n. 2.306/97, foram suspensos por liminar da Justiça Federal, acionada pelas instituiçóes privadas.

Nova inflexão no desenvolvimento desse processo ocorreu no governo Lula, com o Programa Universidade para Todos. ${ }^{3} \mathrm{O}$ ProunI foi ao encontro da demanda de acesso ao ensino superior gratuito, não atendida pelas instituições públicas, e da determinação do Plano Nacional de Educação (Lei n. 10.172, de 9 de janeiro de 2001) de aumentar a taxa de escolarização dos jovens de 18 a 24 anos, no ensino superior, de $12 \%$ para $30 \%$, até o final da década, mas de um modo tal que a participação do setor público fosse igual ou maior a $40 \%$ do alunado.

A primeira configuração do Programa Universidade 4 para Todos foi o Projeto de Lei (PL) n. 3.582, enviado ao Congresso Nacional em maio de 2004. A pressa em implantar o programa, assim como a criação de um fato consumado, de modo que o Congresso não pudesse mudar muito a proposta do MEC, levou o Presidente a baixar a Medida Provisória (MP) n. 213, de 10 de setembro de 2004. ${ }^{5}$ Para facilitar a tramitação, a MP foi ao encontro de parte dos interesses das IES privadas, fortemente representadas na Câmara dos Deputados e no Senado. Muito modificada no Congresso Nacional, a medida provisória resultou na Lei n. 11.096, de 13 de janeiro de 2005, sancionada quando já apareciam os primeiros efeitos do Programa, a partir da adesão de várias instituições.

O desenvolvimento político, desde o projeto de lei até a lei sancionada, passando pela medida provisória e as mudanças introduzidas pelo Congresso, expressa de modo eloqüente a tese deste artigo. Vejamos, em termos gerais, como foi esse desenvolvimento.

A idéia geral do PROUNI era de que, para terem direito à isenção fiscal, as IES privadas ficariam sujeitas a uma contrapartida, na forma de bolsas de gratuidade nos cursos superiores de graduação e seqüenciais de formação específica. Os beneficiados seriam estudantes provenientes de famílias de baixa renda, negros, indígenas e pardos, 
deficientes físicos e professores das redes púbicas de ensino (neste caso, independentemente de situação financeira e racial). Ao invés de se ater apenas às instituições privadas sem fins lucrativos, o programa estendeu essa barganha às instituiçôes privadas particulares, isto é, às que perseguem fins lucrativos, desde que aderissem ao Programa e cumprissem suas condições. Para participarem dele, as IES teriam de firmar documento de adesão, que estipularia as condições previstas para um prazo de dez anos, renovável indefinidamente.

O PL exigiu das IES aderentes a concessão de bolsas integrais aos alunos beneficiados, cuja renda familiar per capita fosse igual ou menor a um salário mínimo. A MP ampliou o número de beneficiados potenciais, alterando essa condição para um salário mínimo e meio, além de admitir bolsas parciais, de metade do valor das mensalidades, para os alunos cuja renda familiar per capita não ultrapassasse três salários mínimos. A lei aprovada pelo Congresso foi além e admitiu bolsas parciais de um quarto do valor da mensalidade para os bolsistas com as mesmas condições financeiras destes últimos.

Os alvos visados foram os estudantes que houvessem cursado e concluído o ensino médio em escola pública, assim como os professores das redes públicas de educação básica. A MP ampliou os destinatários do Programa, ao incluir nele os egressos das escolas privadas que houvessem se beneficiados de bolsa integral, assim como os portadores de necessidades especiais. Em compensação, os professores das escolas públicas seriam beneficiados apenas nos cursos de licenciatura e pedagogia, independentemente de condição financeira ou escolaridade prévia.

Se a tônica das alterações convergiram na facilitação dos critérios de controle das instituições sobre os candidatos a suas bolsas, a possibilidade de contagem, entre os beneficiados, dos bolsistas parciais, reduziu o "preço" da contrapartida à isenção fiscal. A essa vantagem, somou-se outra, esta decisiva no barateamento da bolsa concedida: a quantidade de bolsistas que deveriam ser admitidos pelas instituições aderentes. O PL determinou que as IES oferecessem uma bolsa integral para cada nove alunos do seu efetivo discente, independentemente de elas terem ou não fins lucrativos. As instituições filantrópicas teriam encargos maiores, já que seriam obrigadas a oferecer uma bolsa para cada quatro alunos pagantes. A PMP baixou esse "preço", mas a redução maior foi efetuada no Congresso. A lei aprovada determinou que, 
após uma curta transição, válida apenas para o ano de implantação do Programa (2005), a contrapartida ficasse assim: as instituiçôes não filantrópicas teriam de oferecer uma bolsa integral para cada 10,7 alunos pagantes, ou, alternativamente, uma bolsa integral para cada 22 pagantes e um certo número de bolsas parciais (metade e quarta parte da mensalidade), de modo que, tudo somado, chegasse a $8,5 \%$ da receita bruta. As IEs filantrópicas, por sua vez, seriam obrigadas a oferecer bolsas de gratuidade integrais e parciais $(50 \%$ e $25 \%$ do valor da mensalidade) com valor total igual a $20 \%$ da receita anual efetivamente recebida.

As multas previstas pelo PL para as IES aderentes que descumprissem as normas do Programa (até 1\% do faturamento do ano anterior) foram totalmente suprimidas da medida provisória e da lei.

Promulgada, então, a Lei n. 11.096/2005, as entidades representativas das instituições privadas de ensino manifestaram-se em apoio ao Programa, satisfeitas com as condiçóes estabelecidas, particularmente do "preço" da isenção fiscal que lhes beneficiava.

Tudo somado, o reconhecimento do status de instituições educacionais com fins lucrativos, que aparecia implicitamente na LDB-96, foi explicitado pela lei do PROUNI. Sem subterfúgios, as IES podem se declarar com fins lucrativos, pagar os impostos e contribuições a que estão sujeitas as empresas de serviços e distribuir os lucros abertamente aos seus proprietários ou acionistas. No outro extremo do espectro institucional privado, as instituições filantrópicas são obrigadas a aderir ao Programa e têm de atender a condiçôes menos fáceis do que aquelas. Em conseqüência, já existe um processo de migração de IES desta última condição para aquela, vale dizer, da condição de filantrópicas para a de fins lucrativos. Nessa migração, elas levam consigo o capital acumulado, com base em financiamentos de agências governamentais a juros privilegiados. Em suma, trata-se de doação de capital do setor público para o setor privado.

Como se não bastassem as concessões às entidades lucrativas, o PL n. 920/2007 (um dos componentes do Plano de Desenvolvimento da Educação) prevê a possibilidade das instituições que tiverem dívidas com a União, particularmente com a Receita Federal, abatê-las com a concessão de bolsas de estudo, segundo os critérios do PROUNI, ao qual devem aderir. No momento em que este artigo foi concluído, o projeto de lei tramita na Câmara dos Deputados. 
Um breve comentário se impõe sobre a possível destinação dos recursos da isenção fiscal para as entidades públicas de ensino superior, reclamada por certos críticos. Por mais que seja reprovável esse benefício público à acumulação de capital privado, é preciso reconhecer que esse processo não é reversível para as IES federais, total e automaticamente. Caso ele fosse suprimido, as IES federais não os receberiam. Isso porque apenas os recursos provenientes das contribuiçôes têm destinação específica, e nenhuma delas vão para as IES públicas, direta ou indiretamente. Os recursos provenientes de impostos, por sua vez, não têm destinação específica, a não ser em termos proporcionais, como no FUNDEF e no FUNDEB, este a partir de 2008. Assim, os recursos que iriam para o ensino superior público, caso não houvesse renúncia de impostos, obedeceriam ao tratamento definido pelos orçamentos governamentais, sendo, portanto, indeterminado o montante que reforçaria os orçamentos das IES públicas.

O conjunto de medidas denominadas Plano de Desenvolvimento da Educação incluiu o Decreto n. 6.096, de 24 de abril de 2007, que instituiu o Programa de Apoio a Planos de Reestruturação e Expansão das Universidades Federais (REUNI). Sem embargo de diretrizes de duvidosa eficácia, como a de apoio a "modalidades de graduação, preferencialmente não voltadas à profissionalização precoce e especializada", isto é, o bacharelado interdisciplinar, o programa prevê apoio financeiro ${ }^{6}$ aos projetos de universidades que se dispuserem a reduzir as taxas de evasão, preencher as vagas ociosas e aumentar as vagas de ingresso, especialmente no período noturno. Ainda que o REUNI tenha recebido críticas variadas, principalmente por não levar em conta as peculiaridades das universidades federias, ele pode vir a impulsionar o crescimento do alunado desse segmento do ensino superior.

Em suma, o REUNI está para o segmento federal do setor público, assim como o PROUNI está para o setor privado.

\section{Efeitos divergentes}

A tabela a seguir apresenta o número de alunos matriculados nos três níveis de ensino, segundo dependência administrativa pública ou privada, desde 1965, em intervalos de dez anos. Vejamos que conclusões podemos tirar dela. 
Número de alunos matriculados segundo nível de ensino e dependência administrativa - Brasil, 1965/2005 (em milhōes de alunos)

\begin{tabular}{|c|c|c|c|c|c|}
\hline $\begin{array}{l}\text { NÍVEL DE } \\
\text { ENSINO }\end{array}$ & 1965 & 1975 & 1985 & 1995 & 2005 \\
\hline $\begin{array}{l}\text { Fundamental } \\
\text { público }\end{array}$ & $\begin{array}{l}5,2 \text { [a] } \\
(86,7 \%)\end{array}$ & $\begin{array}{l}17,0{ }^{\text {[c] }} \\
(87,2 \%)\end{array}$ & $\begin{array}{l}21,8 \\
(87,9 \%)\end{array}$ & $\begin{array}{l}28,9 \\
(88,4 \%)\end{array}$ & $\begin{array}{c}30,2 \\
(89,9 \%)\end{array}$ \\
\hline $\begin{array}{l}\text { Fundamental } \\
\text { privado }\end{array}$ & $0,8^{[\mathrm{a}]}$ & $2,5^{[c]}$ & 3,0 & 3,8 & 3,4 \\
\hline $\begin{array}{c}\text { Fundamental } \\
\text { total }\end{array}$ & $6,0^{[a]}$ & $19,5^{[\mathrm{c}]}$ & 24,8 & 32,7 & 33,6 \\
\hline $\begin{array}{l}\text { Médio } \\
\text { público }\end{array}$ & $\begin{array}{r}\quad[\mathrm{b}] \\
0,7 \\
(41,2 \%)\end{array}$ & $\begin{array}{l}\text { [d] } \\
1,1 \\
(57,9 \%)\end{array}$ & $\begin{array}{l}2,0 \\
(66,7 \%)\end{array}$ & $\begin{array}{l}4,2 \\
(77,8 \%)\end{array}$ & $\begin{array}{c}7,9 \\
(87,8 \%)\end{array}$ \\
\hline $\begin{array}{l}\text { Médio } \\
\text { privado }\end{array}$ & $1,0^{[\mathrm{b}]}$ & $0,8^{[\mathrm{d}]}$ & 1,0 & 1,2 & 1,1 \\
\hline $\begin{array}{l}\text { Médio } \\
\text { total }\end{array}$ & $1,7^{[\mathrm{b}]}$ & $1,9^{[\mathrm{d}]}$ & 3,0 & 5,4 & 9,0 \\
\hline $\begin{array}{l}\text { Superior } \\
\text { público }\end{array}$ & $\begin{array}{l}0,09 \\
(56,3 \%)\end{array}$ & $\begin{array}{l}0,4 \\
(36,4 \%)\end{array}$ & $\begin{array}{l}0,6 \\
(42,9 \%)\end{array}$ & $\begin{array}{l}0,7 \\
(38,9 \%)\end{array}$ & $\begin{array}{c}1,2 \\
(27,3 \%)\end{array}$ \\
\hline $\begin{array}{l}\text { Superior } \\
\text { privado }\end{array}$ & 0,07 & 0,7 & 0,8 & 1,1 & 3,2 \\
\hline $\begin{array}{c}\text { Superior } \\
\text { total }\end{array}$ & 0,16 & 1,1 & 1,4 & 1,8 & 4,4 \\
\hline
\end{tabular}

Fontes: 1965: IBGE (Anuário Estatístico do Brasil) e MEC/SEEC (Sinopse Estatística do Ensino Superior). 1975: MEC/SEEC (Sinopses Estatísticas do Ensino). 1985 a 2005: MEC/INEP (Sinopses Estatísticas, capturadas em: www.inep.gov.br)

Notas: Os números entre parênteses representam a percentagem do número de alunos matriculados em instituiçôes públicas de cada nível de ensino, em cada ano da série. [a] Ensino primário; [b] Ensino médio $1^{\circ}$ e $2^{\circ}$ ciclos; [c] Ensino de $1^{\circ}$ grau; [d] Ensino de $2^{\circ}$ grau.

Antes de tudo, uma advertência sobre a leitura dos dados de 1965 e a comparação com os de 1975 . À primeira vista, alguém poderia concluir, equivocadamente, que o número de alunos do ensino fundamental público teria mais do que triplicado na primeira década do regime 
militar. Essa impressão se desfaz pela leitura atenta das observações feitas na tabela, que mostram serem os dados de 1965 referentes ao ensino primário, enquanto que os de 1975 são do ensino de $1^{\circ}$ grau, resultado da justaposição do primário ao ginásio e o fim do exame de admissão. Infelizmente, não foi possível separar os dados do então ensino médio (ginásio + colégio), de modo a se ter uma comparação mais aproximada.

Apesar dessa dificuldade inicial, podemos ver que o ensino púbico aumentou no que chamamos hoje de educação básica, somando primário + médio, $1^{\circ}$ e $2^{\circ}$ graus, e fundamental + médio, no período em foco. De 1965 a 2005, o alunado do ensino público cresceu, na educação básica, de 5,9 para 38,1 milhões, enquanto que o do ensino privado aumentou de 1,8 para 4,4 milhões. Isto quer dizer que as escolas públicas tinham um efetivo discente, em 2005, igual a 6,5 vezes o de 1965 . No mesmo ano, as escolas privadas tinham um alunado igual a 2,4 vezes ao do ano inicial do período.

Passemos agora para a visualização da proporção de alunos das escolas públicas sobre o total do alunado, em cada ano do período. Vemos que a proporção de alunos matriculados nas escolas públicas de ensino obrigatório manteve-se na mesma ordem de grandeza relativa ao longo dos anos: de $86,7 \%$ no primário, em 1965 , a $89,9 \%$ do fundamental, em 2005. Mas, no nível posterior ao obrigatório, o crescimento da participação do setor público foi de grande intensidade: dos $41,2 \%$ do ensino médio (ginásio + colégio), de 1965, aos 87,8\% do ensino médio de 2005, com proporções crescentes ao longo do período.

A conclusão é que a participação das redes públicas no atendimento do ensino obrigatório manteve-se no mesmo patamar, ao longo das quatro décadas do período focalizado. No nível imediatamente após, o crescimento foi marcante. Nesse nível, o setor privado permaneceu com o mesmo contingente discente, em ordem de grandeza, em torno de um milhão de alunos, chegando mesmo a apresentar um pequeno decréscimo no decênio 1995/2005. O setor público, ao contrário, incorporou mais de sete milhôes de alunos, resultado do aumento da procura devido ao crescimento da população, da urbanização e da elevação dos requisitos educacionais para os postos de trabalho.

Todavia, o ensino superior mostrou um quadro totalmente oposto. Nesse nível, o crescimento do setor privado apresentou intensidade 
inédita, superando em muito a velocidade de expansão do ensino público. Enquanto que o número de estudantes das instituições públicas foi multiplicado por 13, de 1965 a 2005 , esse fator foi de 46 para as privadas. $\mathrm{O}$ resultado foi que a participação relativa do setor público, nas matrículas, que era de 56,3\%, no início do período focalizado, despencou para $27,3 \%$ ao seu fim.

\section{Quantidade e qualidade}

O caráter meandroso do desenvolvimento da educação brasileira dificulta chegar-se a uma conclusão segura sobre as tendências futuras. Contudo, não impede que algumas assertivas sejam feitas, assim como certas indagaçóes sobre suas possibilidades, particularmente no que concerne aos efeitos sobre a qualidade do ensino no país. Apresento abaixo as que me parecem mais relevantes.

1 - A ampliação do alunado do ensino fundamental público não deve levar à suposição de que a publicização desse nível esteja próxima de se realizar. Surgem novas formas de privatização, agora para dentro da escola pública, o que se realiza mediante a atuação de ONGs que substituem as funções inerentes às secretarias estaduais e municipais, a exemplo de reforma curricular, a capacitação de professores e até mesmo a atuação direta com os alunos fora das aulas propriamente ditas, quando se dá a extensão da jornada diária.

2 - O aumento quantitativo do alunado do ensino público na educação básica, especialmente no ensino médio, gera nova qualidade. Quer dizer: os alunos não são apenas muitos, eles são outros, em termos sociais e culturais. Este fato exige que se encare o ensino em termos distintos do que se tem feito. Novos contingentes sociais passam a freqüentar a escola, sem as premissas culturais de antes, quando os destinatários eram poucos e selecionados, "espontaneamente", pelas condiçôes de vida das famílias, pela localização das escolas no espaço urbano e pela distribuição das vagas oferecidas, por turno e modalidade de ensino. A ampliação do alunado implica a obsolescência de muito do que deu certo durante décadas, porque a escola torna-se cada vez mais distante das realidades significativas para os alunos. 
Numa frase: os novos contingentes sociais e culturais exigem novos currículos, com tudo o que o termo implica (conteúdos, métodos, espaço, tempo etc.). Repetir o mesmo produzirá efeitos cada vez piores, a menos que sejam dissimulados pela promoção automática.

3 - Foi difícil, mas foi preciso tirar o latim do elenco de disciplinas obrigatórias do ensino secundário, ao início da década de 1960, contra interesses corporativos e religiosos. ${ }^{7}$ Mas, depois da saída do latim, a crítica ao enciclopedismo foi esquecida e o leque de disciplinas do ensino médio aumentou, ao invés de diminuir. Para os poucos e selecionados alunos de ontem, o enciclopedismo curricular era uma conveniente solução: alguma coisa da pletora de disciplinas acabava sendo aprendida. Para os novos contingentes, não, o enciclopedismo é fatal. É compreensível, mas inaceitável que o currículo da educação básica seja transformado, tão cruamente, em espaço de disputa de mercado para os licenciados em certas disciplinas, a exemplo da Filosofia, da Sociologia e da Psicologia - quais serão as próximas? Para a inclusão destas e outras disciplinas no currículo, não faltam justificativas generosas e edificantes, mas, tirando os disfarces, não estará aí um elemento adicional da redução da dimensão pública da educação básica, em proveito de interesses, senão privados, ao menos particulares de grupos corporativos?

4 - A dimensão profissionalizante do ensino médio deve assumir o primeiro plano das prioridades de reforma curricular, se levarmos em conta que metade dos alunos do setor público freqüenta escolas noturnas e muitos deles já trabalham. Esse é um ponto marcante para a construção de nova qualidade do ensino médio que, todavia, não pode ficar refém dos fantasmas ainda vivos da Lei n. 5.692/71, com sua função contenedora do acesso ao ensino superior, nem das apartações discriminatórias do Decreto n. 2.208/97, nem, ainda, da utopia politécnica. Encontrar uma solução curricular prática e viável para o ensino profissionalizante, em todo o nivel médio, é uma urgência para a educação básica de massa.

5 - Quando se fala da qualidade da educação pública, não em termos do mais e do menos, do maior ou do menor rendimento 
diante de certos testes, mas em termos do que se ensina, do que e como se aprende, a questão da laicidade assume o primeiro plano. As dificuldades sentidas pelos professores no interior das escolas, assim como suas perplexidades diante da violência nas ruas levam-nos a evocar a função de controle social e individual do ensino religioso, que teria, também, o papel supletivo de ensinar a ética e a cidadania, como se elas só pudessem ter na religião uma base sólida. Já há indícios dos efeitos deletérios dessa retomada religiosa, dos quais o mais visível é a interiorização dos conflitos religiosos pelas escolas públicas, que ocorre para além de toda a disposição tolerante declarada por agentes e/ou professores. Hoje, mais do que no passado, o ensino laico na escola pública é uma condição necessária da integridade curricular e da liberdade de crença (que inclui a não-crença religiosa), princípio constituinte dos direitos humanos.

6 - A conseqüência primeira do item acima é a efetivação do caráter facultativo do ensino religioso nas escolas públicas. A realidade é que, quando oferecido, ele assume o status de obrigatório, negando-se aos alunos e aos pais o caráter facultativo que essa disciplina tem, por imperativo constitucional: pode ser assistida ou não. $\mathrm{O}$ mais comum é que esse caráter seja omitido, quando não distorcido para os alunos e seus pais, a quem falta a informação legal. Lamentavelmente, quando as direções das escolas assumem o papel que lhes compete e anunciam o caráter facultativo, não têm coisa alguma a oferecer no tempo já curto da jornada de aulas. Aí está uma das grandes lacunas da LDB, cujo projeto aprovado na Câmara dos Deputados continha um dispositivo sobre o oferecimento de alternativa para os alunos que preferissem não ter ensino religioso na escola pública. $\mathrm{Na}$ construção de uma nova qualidade da educação básica do Estado laico, é indispensável que, antes de tudo, os alunos e seus pais estejam cientes do caráter facultativo dessa disciplina, assim como das alternativas cultural e pedagogicamente significativas a que eles têm direito. Aí, sim, o "facultatório" deixará de ser uma triste e repulsiva realidade da escola pública.

7 - O Fundeb é ainda uma incógnita. Parece que haverá maior volume de recursos para o ensino público, o que será bem vindo para alimentar a expansão do setor e a construção de uma 
nova qualidade. Todavia, a opção por um fundo único para a educação básica, ao invés de um mecanismo de financiamento para cada um de seus níveis, assim como as disputas em torno dos termos de sua abrangência, faz temer tanto pela concorrência predatória entre redes estaduais e municipais, quanto pela omissão complacente. Se isso ocorrer, o FUNDEB não representará, para o conjunto da educação básica, o elemento positivo que o FUNDEF trouxe para o ensino fundamental. A despeito dos problemas em sua implantação, ele suprimiu a mediação políticopartidária na distribuição dos recursos entre os níveis estadual e municipal das redes escolares públicas.

8 - A existência de milhares de estudantes matriculados nas instituições de ensino superior de mais baixa qualidade pode representar um poderoso inibidor para que a avaliação desenvolvida pelo sinaEs seja efetiva e conseqüente, de modo que a responsabilidade pela desativação dos cursos ruins não venha a ser transferida da instituição que o ministra para o MEC, que os avalia. Aliás, o processo que resultou na Lei n. 11.096/05 já prenunciava a tendência ao afrouxamento dos critérios. As penalidades pelo mau desempenho foram deslocadas das instituições para os cursos, de modo que elas mantivessem a condição de participantes do PROUNI e não perdessem as bolsas, nem mesmo as dos cursos insuficientes, as quais seriam redistribuídas internamente.

9 - A persistente divisão do ensino superior entre instituições públicas de alto nível (temos quatro delas entre as 500 melhores universidades do mundo) e poucos estudantes, ao lado de um grande número de instituições privadas de baixo nível e muitos alunos, encontra-se ameaçada pela presença de um novo protagonista, a instituição estrangeira. A compra de IES privadas brasileiras já começou e pode aumentar ainda mais se tiverem sucesso os pleitos de certos países na Organização Mundial de Comércio, no sentido de abertura do setor à competição internacional. Se as interessadas imediatas são as entidades que atuam no mercado de massa do ensino superior, deve-se levar em conta que a Universidade de Harvard, membro destacado da Ivy League, já instalou um escritório em São Paulo, primeiro passo para a abertura de cursos em nosso país. 
10 - Finalmente, mas não secundariamente, o caráter meandroso do desenvolvimento da educação brasileira expressa, de um lado, uma crise de hegemonia no que concerne à natureza do Estado republicano e, de outro, o travamento de uma qualidade que não só a educação, mas toda a sociedade brasileira carece, qual seja, a da clareza na distinção entre o público e o privado, hoje confundidos em tantos e tão importantes domínios.

\section{Recebido em junho de 2007 e aprovado em julho de 2007.}

\section{Notas}

1. A definição empírica, útil para este artigo, não elide a necessidade de uma conceituação precisa da dimensão pública e privada das instituições sociais, sobretudo das instituiçõos estatais, numa época em que suas fronteiras parecem borradas no plano político.

2. Na realidade, esse critério de divisão dos recursos do salário-educação proporcionalmente ao número de alunos das redes estadual e municipais foi previsto pela Constituição Estadual do Rio de Janeiro, de 1989. Todavia, esse dispositivo foi suspenso por ação de inconstitucionalidade movida pelo governador Leonel Brizola ao Supremo Tribunal Federal (STF). Após a Lei n. 10.832/03, esse mecanismo foi reposto, não pela Constituição, mas pela legislação federal.

3. Para a redação dessa passagem, baseei-me em Carvalho (2006) e Carvalho e Lopreato (2005).

4. Na linha do senso comum, o Ministério da Educação chamou de universidade todas as instituições de ensino superior e de universitários, os alunos de todas elas.

5. Manifestaçôes reativas vieram de lados opostos: dos que rejeitavam a repetição do processo de compra de vagas em instituições privadas, como se fez generalizadamente no ensino fundamental, e dos que pretendiam "baratear" o preço da "estatização de vagas".

6. Os recursos adicionais, que podem atingir o correspondente a $20 \%$ das despesas de custeio e pessoal, no período de cinco anos, serão destinados à construção e reforma de prédios, aquisição de bens e serviços, assim como despesas de custeio e pessoal para a implantação dos projetos.

7. Ainda hoje há quem diga que a deterioração do ensino foi provocada pela supressão do latim.

\section{Referências bibliográficas}

BONAMINO, A. O público e o privado na educação brasileira: inovações e tendências a partir dos anos 1980. Revista Brasileira de História da Educação, Campinas, n. 5, p. 253-276, jan./jun. 2003. 
CARVALHO, C.H.A. O PROUNI no governo Lula e o jogo político em torno do acesso ao ensino superior. Educação \& Sociedade, Campinas, v. 27, n. 96, p. 979-1000, out. 2006.

CARVALHO, C.H.A.; LOPREATO, F.L.C. Finanças públicas, renúncia fiscal e o Prouni no Governo Lula. Impulso, Piracicaba, v. 16, n. 40, p. 93-104, maio/ago. 2005.

CUNHA, L.A. (Org.). Escola pública, escola particular e a democratização do ensino. São Paulo: Cortez, 1985.

CUNHA, L.A. Educação, Estado e democracia no Brasil. São Paulo: Cortez, 1991.

CUNHA, L.A. Desenvolvimento desigual e combinado no ensino superior: Estado e mercado. Educação \& Sociedade, Campinas, v. 25, n. 88, p. 795-817, out. 2004.

CURY, C.R.J. A educação escolar no Brasil: o público e o privado. Trabalho, Educação \& Saúde, Rio de Janeiro, v. 4, n. 2, p. 143-158, set. 2006.

FRANCO, E. Entidades mantenedoras sem fins lucrativos: o convívio com o rigor das normas do Decreto 2.207/97. Estudos, Brasília, DF, v. 15, n. 19, p. 9-18, jun. 1997.

LOMBARDI, J.C.; JACOMELI, M.R.M.; SILVA, T.M.T. (Org.). O público e o privado na história da educação brasileira: concepções e práticas educativas. Campinas: Autores Associados, 2005.

LUCE, M.B. Diversidade e diferenciação do público e do privado na educação superior do Brasil. Disponível em: <http://www.ufrgs.br/ faced/mbluce/LUCEforlaSA2001.pdf>. Acesso em: 23 maio 2007.

VIEIRA, S.L. O público e o privado nas tramas da LDB. In: BRZEZINSKI, I. (Org.). LDB interpretada: diversos olhares se entrecruzam. São Paulo: Cortez, 1997. p. 65-81.

XAVIER, L.N. Oscilação do público e do privado na história da educação brasileira. Revista Brasileira de História da Educação, Campinas, n. 5, jan./jun. 2003 . 